\title{
The Effects of Combined Renal Vasodilatation and Pressor Agents on Renal Hemodynamics and the Tubular Reabsorption of Sodium*
}

\author{
Laurence E. Earley $†$ and Robert M. Friedler \\ (From the Thorndike Memorial Laboratory, Second and Fourth [Harvard] Medical Services, \\ Boston City Hospital, and the Department of Medicine, Harvard Medical \\ School, Boston, Mass.)
}

A considerable body of evidence indicates that the net tubular reabsorption of sodium may be diminished during extracellular volume expansion, independent of the tubular effects of salt-retaining hormones. Since the report by De Wardener, Mills, Clapham, and Hayter (1), several other studies employing clearance techniques have demonstrated diminished net tubular reabsorption of sodium during saline loading in the dog (2-5). In addition, Dirks, Cirksena, and Berliner have reported recently that fractional reabsorption in the proximal nephron of the dog may be diminished strikingly during saline loading (6). Thus, natriuresis in response to salt loading could be due largely to diminished tubular reabsorption of sodium unrelated to aldosterone. However, such studies have not revealed mechanisms and pathways whereby expansion of the extracellular volume leads to diminished reabsorption of sodium. We recently suggested that increased renal blood flow, and perhaps increased medullary blood flow specifically, may be one factor that by way of intrarenal mechanisms contributes to diminished reabsorption of sodium during saline loading (5). Furthermore, natriuresis in the absence of salt loading accompanies increased renal blood flow when local vasodilatation is produced by a variety of agents $(7-13)$, and we have observed that the unilateral natriuresis accompanying increased renal blood flow during the renal arterial infusion of acetylcholine is due in part to diminished net tubular reab-

* Submitted for publication September 29, 1965 ; accepted December 16, 1965.

Aided in part by grants AM-5401-04 from the National Institutes of Health and NsG595 from the National Aeronautics and Space Administration.

$\dagger$ Address requests for reprints to Dr. Laurence $\mathrm{E}$. Earley, Boston City Hospital, 818 Harrison Ave., Boston, Mass. 02118. sorption of sodium (14). Leyssac has suggested that angiotensin may depress proximal tubular reabsorption (15), and it has been demonstrated that under certain conditions angiotensin may produce natriuresis (16-19). If the reabsorption of sodium distally to the proximal convolution relates in part in some inverse manner to blood flow, then the vasoconstrictor effects of angiotensin could limit the natriuretic effect that the agent could exert by way of depressing proximal tubular reabsorption. Such a dual effect of angiotensin on tubular reabsorption and renal blood flow could explain the inconsistent effects of the agent on sodium excretion. The present studies were therefore undertaken to examine the combined effects of renal vasodilatation and angiotensin on tubular reabsorption and sodium excretion. By producing unilateral renal vasodilatation it was possible to compare the effects of angiotensin on sodium excretion in two kidneys receiving different blood flows in the same animal.

\section{Methods}

Twenty-one mongrel dogs of either sex ranging in weight from 19.1 to $26.8 \mathrm{~kg}$ were deprived of food and water for 18 hours and anesthetized with pentobarbital. The animals were respired automatically with room air. Each ureter was cannulated through flank incisions, and a 23-gauge needle was inserted in the direction of flow into one renal artery (usually the left) near its origin at the aorta. The techniques used for collecting and handling renal venous blood samples have been described elsewhere (14). Arterial blood samples were collected, and arterial pressure was measured through a catheter inserted into the aorta through a femoral artery. Approximately 3 hours before experimental collections each animal received an im injection containing $5 \mathrm{U}$ of Pitressin Tannate ${ }^{1}$ and $10 \mathrm{mg}$ of deoxycorticosterone acetate. ${ }^{2}$ Two hours before experimental measurements an iv in-

\footnotetext{
1 Parke, Davis, Detroit, Mich.

2 Organon, West Orange, N. J.
} 
fusion of $0.9 \%$ saline was begun at a constant rate between 0.4 and $0.5 \mathrm{ml}$ per minute to deliver inulin at 20 to $25 \mathrm{mg}$ per minute, $p$-aminohippurate at 3.2 to $3.8 \mathrm{mg}$ per minute, vasopressin (Pitressin) ${ }^{1}$ at 40 to $60 \mathrm{mU}$ per $\mathrm{kg}$ per hour, and deoxycorticosterone ${ }^{3}$ at 25 to $30 \mu \mathrm{g}$ per minute. The total rate of infusion of this maintenance solution and infusions into the renal venous, renal arterial, and femoral arterial catheters was approximately $2.0 \mathrm{ml}$ per minute. A minimum of 2 hours elapsed after completing the operative procedure before beginning experimental collections. Renal venous and arterial blood samples were collected simultaneously at the midpoint of clearance periods, except in some cases where short periods (5 minutes) were employed during stable phases of the experiment and blood samples were collected during alternate clearance periods. Clearances were not calculated during transitional phases of the experiments when urine flow was changing abruptly.

The following experimental protocols were employed, and 3 to 6 clearance periods were collected during each phase of the experiment. After collection of control periods the renal arterial infusion was changed to saline containing acetylcholine bromide, ${ }^{4}$ bradykinin, ${ }^{5}$ or kalli$\operatorname{din}^{5}$ to deliver $40 \mu \mathrm{g}, 5 \mu \mathrm{g}$, or 1 to $3 \mu \mathrm{g}$ per minute, re-

${ }^{3}$ Steraloids, Queens, N. Y.

4 Eastman Organic Chemicals, Rochester, N. Y.

5 Kindly supplied by Sandoz Pharmaceuticals, Hanover, N. J. spectively. After collections for clearances during a stable phase of unilateral renal vasodilatation, angiotensin II (Hypertensin) 6 was added to the renal arterial infusion in 6 experiments at a constant rate ranging from 0.1 to $0.5 \mu \mathrm{g}$ per minute. After collections during combined renal vasodilatation and angiotensin infusion, the angiotensin was usually discontinued, and after further collections the vasodilator was discontinued, and additional control collections were made. In 11 other experiments a similar protocol was followed except that angiotensin was infused intravenously at a rate of 1.0 to $10.0 \mu \mathrm{g}$ per minute. In 4 experiments the infusion of the vasodilator was discontinued while continuing the infusion of angiotensin, and in 5 experiments angiotensin was infused before starting the infusion of the vasodilator. The exact sequences of drug infusions are detailed in Tables II and III. In all instances 10 to 30 minutes was allowed for stabilization of blood pressure and urine flow before making collections during each phase of the experiments.

In 5 experiments the effects of equipressor infusions of angiotensin and norepinephrine were compared during unilateral renal vasodilatation. After control clearance periods an infusion of acetylcholine was begun into the left renal artery at $40 \mu \mathrm{g}$ per minute. Further collections were made, and then an infusion of angiotensin or norepinephrine was begun intravenously at 5 or $10 \mu \mathrm{g}$ per min-

${ }^{6}$ Ciba Pharmaceuticals, Summit, N. J.

TABLE I

Effects of systemically infused angiotensin on renal hemodynamics and electrolyte excretion in the presence of unilateral renal vasodilatation in experiment no. $2^{*}$

\begin{tabular}{|c|c|c|c|c|c|c|c|c|c|c|c|c|c|c|c|}
\hline \multirow[b]{2}{*}{ Time } & \multicolumn{2}{|c|}{ V } & \multicolumn{2}{|c|}{ GFR } & \multicolumn{2}{|c|}{ CPAH $_{\text {Pat }}$} & \multirow{2}{*}{$\underset{\mathbf{E}}{\text { EPA }_{\mathbf{P}}}$} & \multirow{2}{*}{$\underset{\mathbf{L}}{\mathbf{R} P \mathbf{F}}$} & \multirow{2}{*}{$\underset{\mathbf{L}}{\mathrm{NCPF}}$} & \multicolumn{2}{|c|}{$\mathrm{UNaV}_{\mathrm{Na}}$} & \multicolumn{2}{|c|}{$\mathrm{UkV}_{\mathrm{K}}$} & \multirow[b]{2}{*}{$\mathbf{P}_{\mathrm{Na}}$} & \multirow[b]{2}{*}{$\begin{array}{l}\text { Arterial } \\
\text { pressure }\end{array}$} \\
\hline & $\mathbf{R}$ & $\mathrm{L}$ & $\mathbf{R}$ & $\bar{L}$ & $\mathbf{R}$ & $\mathbf{L}$ & & & & $\mathbf{R}$ & $\mathrm{L}$ & $\mathbf{R}$ & $\mathbf{L}$ & & \\
\hline $\min$ & \multicolumn{2}{|c|}{$m l / m i n$} & \multicolumn{2}{|c|}{$m l / \min$} & \multicolumn{2}{|c|}{$\mathrm{ml} / \mathrm{min}$} & & $m i / /$ & $m i /$ & \multicolumn{2}{|c|}{$\mu E q / \min$} & \multicolumn{2}{|c|}{$\mu E q / \min$} & $m E q / L$ & $m m H g$ \\
\hline $0-15$ & 0.31 & 0.21 & 51 & 41 & 137 & 110 & 0.867 & 127 & 17 & 39 & 31 & 26 & 20 & 143 & 124 \\
\hline $15-43$ & 0.37 & 0.30 & 51 & 53 & 145 & 149 & 0.868 & 174 & 25 & 36 & 35 & 29 & 29 & 144 & 120 \\
\hline $43-52$ & 0.71 & 0.51 & 52 & 52 & 170 & 171 & 0.844 & 203 & 32 & 45 & 34 & 38 & 35 & 144 & 110 \\
\hline \multicolumn{16}{|c|}{ Begin infusion of acetylcholine bromide at $40 \mu \mathrm{g}$ per minute into left renal artery } \\
\hline $52-62$ & 1.24 & 2.26 & & & & & & & & 74 & 154 & 42 & 61 & & 119 \\
\hline $62-68$ & 170 & 314 & 51 & 50 & 174 & 220 & 0.686 & 321 & 101 & 99 & 214 & 43 & 50 & 146 & 125 \\
\hline $68-74$ & 1.75 & 2.77 & 49 & 44 & 158 & 206 & 0.717 & 287 & 81 & 103 & 186 & 40 & 47 & 147 & 120 \\
\hline $74-80$ & 1.58 & 2.47 & 48 & 44 & 146 & 189 & 0.727 & 260 & 71 & 96 & 158 & 38 & 44 & 146 & 117 \\
\hline \multicolumn{16}{|c|}{ Begin infusion of angiotensin $5.0 \mu \mathrm{g}$ per minute intravenously } \\
\hline $80-92$ & 0.56 & 5.16 & & & & & & & & 36 & 402 & 17 & 57 & & \\
\hline $92-103$ & 0.38 & 6.76 & 58 & 47 & 107 & 125 & 0.782 & 160 & 35 & 20 & 573 & 25 & 47 & 149 & 193 \\
\hline $103-114$ & 0.33 & 4.21 & 38 & 42 & 76 & 112 & 0.836 & 134 & 22 & 16 & 327 & 20 & 36 & 148 & 183 \\
\hline $114-120$ & 0.25 & 4.00 & 33 & 40 & 100 & 104 & 0.845 & 123 & 19 & 10 & 300 & 16 & 36 & 149 & 170 \\
\hline \multicolumn{16}{|c|}{ Discontinue infusion of angiotensin } \\
\hline $120-142$ & 0.22 & 1.68 & & & & & & & & 6 & 108 & 17 & 27 & & 137 \\
\hline $142-152$ & 0.17 & 0.41 & 40 & 37 & 97 & 105 & 0.856 & 123 & 18 & 4 & 20 & 17 & 21 & 149 & 103 \\
\hline $152-162$ & 0.16 & 0.40 & 38 & 36 & 92 & 106 & 0.841 & 126 & 20 & 3 & 20 & 17 & 22 & 147 & 100 \\
\hline \multicolumn{16}{|c|}{ Discontinue infusion of acetylcholine } \\
\hline $187-202$ & 0.18 & 0.20 & 40 & 39 & 102 & 99 & 0.879 & 113 & 14 & 4 & 5 & 24 & 22 & 147 & 115 \\
\hline $202-217$ & 0.18 & 0.20 & 41 & 37 & 104 & 101 & 0.870 & 116 & 15 & 5 & 6 & 26 & 24 & 146 & 115 \\
\hline
\end{tabular}

* Abbreviations are as follows: $\mathrm{V}=$ rate of urine flow; $\mathrm{GFR}=$ glomerular filtration rate (clearance of inulin); $\mathrm{C}_{\mathrm{PAH}}=\mathrm{clearance}$ of $p$-amino-

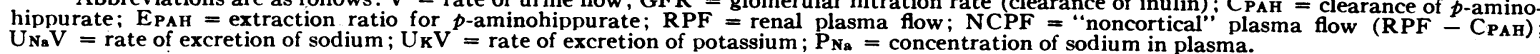


ute, respectively. When further periods of stable urine flow had been collected, the infusion of the pressor agent was discontinued, and approximately 30 minutes was allowed for blood pressure and urine flow to stabilize. Then an intravenous infusion of the alternate pressor agent was begun and adjusted to a rate producing the same blood pressure as during the infusion of the first pressor agent. After collections during stable blood pressure and urine flow the same procedure was followed to return to the first pressor agent.
Analytical procedures for inulin, $p$-aminohippurate, sodium, potassium, and osmolality were the same as employed previously (14). Arterial blood pressure was recorded by a Sanborn pressure transducer and recorder. Renal plasma flow (RPF) was calculated from the clearance of $p$-aminohippurate $\left(\mathrm{C}_{\mathrm{PAH}}\right)$ and the extraction ratio for $\mathrm{PAH}\left(\mathrm{E}_{\mathrm{PAH}}\right) \quad\left(\mathrm{RPF}=\mathrm{C}_{\mathrm{PAH}} / \mathrm{E}_{\mathrm{PAH}}\right)$. "Noncortical" plasma flow (NCPF) was calculated as the difference between RPF and $\mathrm{C}_{\mathrm{PAH}}(\mathrm{NCPF}=\mathrm{RPF}-$ $\left.\mathrm{C}_{\mathrm{PAH}}\right)$.

TABLE II

Effects of combined intravenously infused angiotensin and unilateral (left) renal vasodilatation on renal hemodynamics and sodium excretion*

\begin{tabular}{|c|c|c|c|c|c|c|c|c|c|c|c|}
\hline \multirow[b]{2}{*}{ Experiment } & & \multicolumn{2}{|c|}{ GFR } & \multicolumn{2}{|c|}{$\mathrm{CPAH}_{\mathrm{PAH}}$} & \multirow{2}{*}{$\underset{\mathrm{L}}{\mathrm{RPF}}$} & \multicolumn{2}{|c|}{$\mathrm{UNaV}_{\mathrm{Na}}$} & \multirow{2}{*}{$P_{\mathrm{Na}}$} & \multirow{2}{*}{$\begin{array}{l}\text { Arterial } \\
\text { pressure }\end{array}$} & \multirow{2}{*}{$\underset{\text { tensin }}{\text { Angio- }}$} \\
\hline & & $\mathbf{R}$ & $\mathbf{L}$ & $\mathbf{R}$ & $\mathbf{L}$ & & $\mathbf{R}$ & L & & & \\
\hline & & \multicolumn{2}{|c|}{$m l / m i n$} & \multicolumn{2}{|c|}{$\mathrm{ml} / \mathrm{min}$} & $m l / \min$ & \multicolumn{2}{|c|}{$\mu E q / \min$} & $m E q / L$ & $m m \mathrm{Hg}$ & $\mu g / \min$ \\
\hline \multirow[t]{4}{*}{1.} & Control & 81 & 82 & 209 & 215 & 242 & 172 & 150 & 149 & 142 & 10.0 \\
\hline & Acetylcholine & 64 & 75 & 160 & 257 & 312 & 98 & 229 & 148 & 128 & \\
\hline & Acetylcholine and angiotensin & 80 & 77 & 146 & 215 & 254 & 11 & 409 & 148 & 185 & \\
\hline & Acetylcholine & 49 & 65 & 145 & 210 & 255 & 3 & 18 & 148 & 105 & \\
\hline \multirow[t]{4}{*}{3.} & Control & 44 & 48 & 120 & 135 & 152 & 138 & 184 & 152 & 127 & 5.0 \\
\hline & Acetylcholine & 43 & 43 & 130 & 191 & 272 & 90 & 196 & 151 & 125 & \\
\hline & Acetylcholine and angiotensin & 39 & 39 & 83 & 130 & 175 & 25 & 255 & 152 & 153 & \\
\hline & Acetylcholine & 26 & 21 & 81 & 109 & 155 & 2 & 2 & 152 & 97 & \\
\hline \multirow[t]{5}{*}{4.} & Control & 29 & 31 & 72 & 78 & 92 & 177 & 193 & 143 & 131 & 2.5 \\
\hline & Acetylcholine & 32 & 36 & 84 & 109 & 129 & 247 & 424 & 143 & 125 & \\
\hline & Acetylcholine and angiotensin & 27 & 30 & 56 & 85 & 106 & 104 & 572 & 143 & 162 & \\
\hline & Acetylcholine & 25 & 31 & 67 & 90 & 115 & 37 & 295 & 145 & 110 & \\
\hline & Control & 26 & 34 & 65 & 83 & 95 & 38 & 89 & 146 & 115 & \\
\hline \multirow[t]{4}{*}{5.} & Control & 26 & 36 & 60 & 83 & 90 & 190 & 193 & 148 & 158 & 2.0 \\
\hline & Acetylcholine & 25 & 41 & 63 & 139 & 160 & 191 & 729 & 149 & 153 & \\
\hline & Acetylcholine and angiotensin & 21 & 42 & 43 & 114 & 126 & 40 & 933 & 148 & 183 & \\
\hline & Acetylcholine & 22 & 40 & 59 & 128 & 141 & 13 & 307 & 150 & 120 & \\
\hline \multirow[t]{4}{*}{6.} & Control & 29 & 29 & 66 & 66 & 77 & 250 & 171 & 143 & 182 & 2.5 \\
\hline & Acetylcholine & 29 & 29 & 72 & 108 & 136 & 156 & 264 & 145 & 165 & \\
\hline & Acetylcholine and angiotensin & 31 & 32 & 80 & 110 & 138 & 286 & 498 & 145 & 224 & \\
\hline & Acetylcholine & 20 & 28 & 48 & 92 & 111 & 107 & 146 & 145 & 128 & \\
\hline \multirow[t]{4}{*}{7.} & Control & 41 & 33 & 85 & 75 & 89 & 54 & 89 & 158 & 133 & 2.0 \\
\hline & Kallidin & 36 & 32 & 72 & 103 & 151 & 39 & 242 & 159 & 131 & \\
\hline & Kallidin and Angiotensin & 34 & 35 & 57 & 89 & 129 & 120 & 507 & 158 & 146 & \\
\hline & Angiotensin & 31 & 30 & 57 & 56 & 69 & 139 & 310 & 156 & 151 & \\
\hline \multirow[t]{5}{*}{8.} & Control & 24 & 26 & 62 & 69 & 78 & 236 & 330 & 144 & 130 & 1.0 \\
\hline & Kallidin & 18 & 25 & 46 & 70 & 85 & 117 & 340 & 144 & 124 & \\
\hline & Control & 19 & 20 & 52 & 54 & 62 & 66 & 147 & 144 & 118 & \\
\hline & Angiotensin & 19 & 20 & 47 & 49 & 55 & 170 & 308 & 143 & 147 & \\
\hline & Angiotensin and kallidin & 13 & 20 & 32 & 52 & 65 & 82 & 358 & 143 & 134 & \\
\hline \multirow[t]{8}{*}{9.} & Control & 63 & 57 & 174 & 161 & 183 & 254 & 281 & 147 & 141 & 2.0 \\
\hline & Kallidin & 56 & 55 & 154 & 206 & 249 & 198 & 355 & 146 & 133 & \\
\hline & Control & 61 & 54 & 168 & 151 & 172 & 160 & 156 & 146 & 133 & \\
\hline & Angiotensin & 59 & 54 & 109 & 105 & 114 & 261 & 341 & 147 & 179 & \\
\hline & Angiotensin and kallidin & 54 & 48 & 100 & 132 & 161 & 108 & 381 & 148 & 164 & \\
\hline & Angiotensin & 49 & 47 & 88 & 83 & 89 & 89 & 123 & 149 & 169 & \\
\hline & Angiotensin and acetylcholine & 40 & 50 & 74 & 120 & 165 & 43 & 518 & 148 & 156 & \\
\hline & Acetylcholine & 36 & 50 & 88 & 159 & 193 & 23 & 268 & 149 & 122 & \\
\hline 10. & Control & 50 & 48 & 145 & 142 & 152 & 89 & 90 & 143 & 133 & 2.5 \\
\hline & Bradykinin & 49 & 49 & 152 & 269 & 349 & 70 & 92 & 143 & 127 & . \\
\hline & Bradykinin and angiotensin & 46 & 45 & 101 & 187 & 224 & 227 & 214 & 143 & 168 & \\
\hline & Angiotensin & 44 & 43 & 88 & 95 & 105 & 262 & 156 & 143 & 171 & \\
\hline & Control & 42 & 44 & 129 & 119 & 137 & 23 & 22 & 144 & 122 & \\
\hline
\end{tabular}

* Each phase of experiments is the mean of multiple uniform collection periods, and phases of experiments are consecutive. Transition periods of 5 to 25 minutes when drug infusions were started or stopped and when urine flow was abruptly changing have been omitted from the calculations. of 5 to 25 minutes when drug infusions were started or stopped and when urine flow was abruptly changing have been omitted from the 
TABLE III

Effects of combined renal arterial infusions of acetylcholine and angiotensin on renal hemodynamics and sodium excretion*

\begin{tabular}{|c|c|c|c|c|c|c|c|c|c|c|c|}
\hline \multirow[b]{2}{*}{ Experimen } & & \multicolumn{2}{|c|}{ GFR } & \multicolumn{2}{|c|}{ CPAH } & \multirow{2}{*}{$\underset{L}{R P F}$} & \multicolumn{2}{|c|}{$\mathrm{UNaV}$} & \multirow[b]{2}{*}{$P_{\mathrm{Na}}$} & \multirow{2}{*}{$\begin{array}{l}\text { Arterial } \\
\text { pressure }\end{array}$} & \multirow{2}{*}{$\underset{\text { tensin }}{\text { Angio- }}$} \\
\hline & & $\mathbf{R}$ & $\mathbf{L}$ & $\mathbf{R}$ & $\mathrm{L}$ & & $\mathbf{R}$ & $\mathrm{L}$ & & & \\
\hline & & \multicolumn{2}{|c|}{$m l / \min$} & \multicolumn{2}{|c|}{$\mathrm{ml} / \mathrm{min}$} & $\operatorname{ml} / \min$ & \multicolumn{2}{|c|}{$\mu E q / \min$} & $m E q / L$ & $m m \mathrm{Hg}$ & $\mu g / \min$ \\
\hline \multirow[t]{5}{*}{11.} & Control & 44 & 45 & 100 & 98 & 106 & 140 & 161 & 147 & & 0.5 \\
\hline & Acetylcholine & 45 & 51 & 113 & 206 & 257 & 101 & 350 & 147 & & \\
\hline & Acetylcholine and angiotensin & 40 & 48 & 78 & 134 & 151 & 17 & 359 & 148 & & \\
\hline & Acetylcholine & 37 & 47 & 96 & 171 & 225 & 14 & 112 & 148 & & \\
\hline & Control & 40 & 47 & 110 & 116 & 137 & 7 & 36 & 148 & & \\
\hline \multirow[t]{7}{*}{12.} & Control & 44 & 39 & 170 & 152 & 186 & 155 & 188 & 146 & 147 & 0.5 \\
\hline & Angiotensin & 44 & 34 & 116 & 93 & 107 & 140 & 209 & 146 & 161 & \\
\hline & Control & 43 & 33 & 170 & 136 & 172 & 77 & 74 & 146 & 133 & \\
\hline & Acetylcholine & 39 & 38 & 166 & 205 & 330 & 33 & 239 & 146 & 118 & \\
\hline & Acetylcholine and angiotensin & 36 & 41 & 104 & 158 & 231 & 16 & 520 & 146 & 136 & \\
\hline & Acetylcholine & 34 & 40 & 117 & 185 & 268 & 6 & 175 & 147 & 106 & \\
\hline & Control & 36 & 32 & 114 & 110 & 136 & 8 & 7 & 147 & 104 & \\
\hline \multirow[t]{7}{*}{13.} & Control & 60 & 60 & 169 & 171 & 191 & 256 & 262 & 149 & 192 & 0.25 \\
\hline & Angiotensin & 61 & 60 & 154 & 146 & 160 & 303 & 271 & 149 & 195 & \\
\hline & Control & 61 & 56 & 218 & 206 & 247 & 157 & 125 & 149 & 146 & \\
\hline & Acetylcholine & 52 & 55 & 188 & 230 & 277 & 104 & 195 & 149 & 135 & \\
\hline & Acetylcholine and angiotensin & 50 & 55 & 132 & 179 & 205 & 43 & 297 & 149 & 153 & \\
\hline & Acetylcholine & 46 & 45 & 220 & 192 & 227 & 9 & 50 & 148 & 123 & \\
\hline & Control & 54 & 56 & 183 & 198 & 228 & 20 & 21 & 150 & 123 & \\
\hline \multirow[t]{5}{*}{14.} & Control & 69 & 78 & 140 & 164 & 186 & 238 & 250 & 145 & 179 & 0.5 \\
\hline & Acetylcholine & 76 & 83 & 155 & 252 & 324 & 150 & 404 & 144 & 142 & \\
\hline & Acetylcholine and angiotensin & 70 & 81 & 127 & 228 & 302 & 70 & 626 & 143 & 163 & \\
\hline & Angiotensin & 71 & 65 & 129 & 112 & 126 & 71 & 91 & 142 & 164 & \\
\hline & Control & 74 & 72 & 164 & 178 & 208 & 65 & 33 & 142 & 120 & \\
\hline \multirow[t]{6}{*}{15.} & Control & 64 & 68 & 201 & 261 & $\dagger$ & 40 & 115 & 143 & 137 & 0.5 \\
\hline & Angiotensin & 70 & 56 & 168 & 119 & & 26 & 15 & 142 & 143 & \\
\hline & Control & 64 & 65 & 211 & 260 & & 9 & $79^{\circ}$ & 144 & 130 & \\
\hline & Acetylcholine & 62 & 71 & 217 & 325 & & 2 & 86 & 144 & 126 & \\
\hline & Acetylcholine and angiotensin & 63 & 57 & 164 & 176 & & 3 & 136 & 144 & 145 & \\
\hline & Acetylcholine & 71 & 68 & 243 & 301 & & 3 & 90 & 145 & 135 & \\
\hline \multirow[t]{4}{*}{16.} & Control & 43 & 42 & 96 & 97 & 112 & 109 & 163 & 147 & 139 & 0.1 \\
\hline & Acetylcholine & 43 & 45 & 110 & 155 & 261 & 71 & 352 & 148 & 120 & \\
\hline & Acetylcholine and angiotensin & 45 & 46 & 96 & 133 & 191 & 62 & 477 & 149 & 120 & \\
\hline & Acetylcholine & 34 & 46 & 81 & 156 & 241 & 27 & 344 & 149 & 104 & \\
\hline
\end{tabular}

* Infusions into left renal artery.

$\dagger$ Extraction of PAH not measured in this experiment.

\section{Results}

The effects of angiotensin in the presence of unilateral renal vasodilatation. Details of a representative experiment are given in Table I, and the results of 15 other experiments are summarized in Tables II and III. The renal arterial infusion of either acetylcholine, bradykinin, or kallidin resulted in an ipsilateral increase in urine flow within 60 seconds after infusion of the vasodilator was begun. In the experimental kidney RPF increased by an average of $94 \mathrm{ml}$ per minute (range, 7 to 197 $\mathrm{ml}$ per minute), and $\mathrm{E}_{\mathbf{P A H}}$ decreased by an average of 0.11 (range, 0.01 to 0.27 ). The $\mathrm{C}_{\mathrm{PAH}}$ by the control kidney was usually unchanged or slightly decreased during this phase of unilateral renal vasodilatation. Sodium excretion by the vasodi- lated kidneys increased by an average of $132 \mu \mathrm{Eq}$ per minute (range, 2 to $536 \mu \mathrm{Eq}$ per minute), and sodium excretion by the control kidneys was usually decreased moderately. This increased renal blood flow and sodium excretion by the vasodilated kidneys was associated with unchanged or decreased glomerular filtration in 8 of these $16 \mathrm{ex}-$ periments (experiment 2, Table I; experiments 1,3 , and 6 to 9 , Table II ; and experiment 13, Table III).

In 6 of the 16 experiments (experiments 11 to 16, Table III) angiotensin was infused into the renal artery of the vasodilated kidney, and in the remaining 10 experiments (Tables I and II) angiotensin was infused intravenously during continued infusion of the vasodilator into the renal 
artery. For reasons to be discussed the effects of the renal arterial infusion of angiotensin were usually indistinguishable from the effects of the systemic infusions, and therefore results of all 16 experiments are discussed together.

When the infusion of angiotensin was begun in the presence of unilateral renal vasodilatation, urine flow from the vasodilated kidney increased within 5 to 20 minutes. An earlier rise occurred in the mean arterial blood pressure, and during stable clearance periods mean arterial pressure was elevated by an average of $31 \mathrm{~mm} \mathrm{Hg}$ (range, 0 to $61 \mathrm{~mm} \mathrm{Hg}$ ) above the levels present during vasodilatation before the infusion of angiotensin. Angiotensin resulted in an increased excretion of sodium by the vasodilated kidney that averaged $141 \mu \mathrm{Eq}$ per minute greater than the rates during vasodilatation alone (range of increase, 9 to 281 $\mu \mathrm{Eq}$ per minute). In each experiment angiotensin resulted in decreased $\mathrm{C}_{\mathrm{PAH}}$, decreased RPF (Tables I to IV), and usually increased $E_{\mathbf{P A H}}$ (Figure 1) in the vasodilated kidney. This reduction of hemodynamics and increased excretion of sodium was associated with unchanged or reduced glomerular filtration (below the level present during the vasodilatation alone) in 10 of the 16 experiments (experiment 2, Table I; experiments 3,4 , and 8 to 10 , Table II ; and experiments 11 and 13 to 15 , Table III). Thus, the infusion of angiotensin was accompanied by further increases in sodium excretion by the vasodilated kidney despite a reduction in renal plasma flow and usually a reduction in GFR and filtered sodium. When the infusion of angiotensin was discontinued in the presence of continued renal vasodilatation (experiment 2, Table I ; experiments 1,3 to 6 , and 9, Table II ; and experiments 11 to 13,15 , and 16 , Table III), urine flow and sodium excretion decreased, usually within 25 minutes. This diminished excretion of sodium after discontinuing the infusion of angiotensin was usually accompanied by an increased RPF and decreased $\mathrm{E}_{\mathrm{PAH}}$. Glomerular filtration often, but not always, decreased after stopping the infusion of angiotensin.

Control kidneys. The infusion of angiotensin usually resulted in large decreases in $\mathrm{C}_{\mathbf{P A H}}$ in the nonvasodilated control kidneys (average decrease, $29 \mathrm{ml}$ per minute), and $\mathrm{C}_{\mathbf{P A H}}$ in the control kidney during angiotensin infusion was always lower than $\mathrm{C}_{\mathrm{PAH}}$ in the vasodilated kidney. In 3 experiments

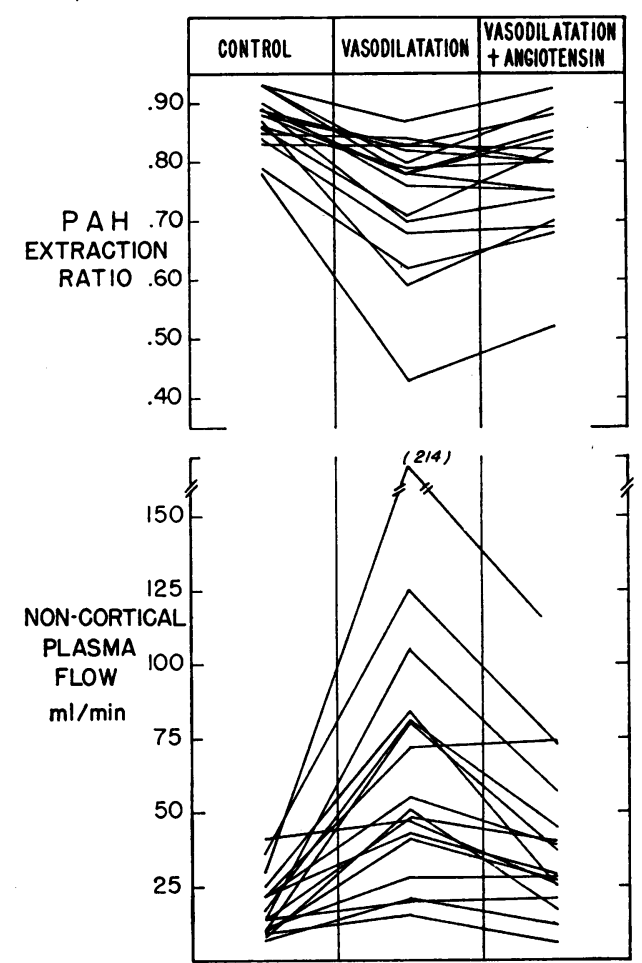

Fig. 1. EFfects of infusion of ANGIOTENSIN DURING UNILATERAL RENAL VASODILATATION ON THE EXTRACTION RATIO OF $p$-AMINOHIPPURATE "( $E_{P A H}$ ) AND "NONCORTICAL PLASMA FLOW." The means of three or more uniform collections from the vasodilated kidneys are represented in each column for each experiment (experiments 1 to 16 , 20, 21). Vasodilatation alone usually decreased $E_{\text {PAH }}$ and increased noncortical plasma flow. The superimposition of angiotensin usually increased $E_{P A B}$ and decreased noncortical plasma flow. The Figure represents the same collection periods summarized in Tables I to IV.

(experiments 6, 7, and 10, Table II) small increases in sodium excretion by the control kidney occurred during the systemic infusion of angiotensin. However, in the remaining 13 experiments the excretion of sodium by the control kidney decreased during the infusion of angiotensin at a time when marked natriuresis was present in the vasodilated kidney. Although GFR in control kidneys was usually decreased during the infusion of angiotensin, in 8 of the 16 experiments (experiments $1,3,6,7,9$, and 10 , Table II ; experiments 15 and 16 , Table III) GFR in control kidneys during the infusion of angiotensin was no more than $1 \mathrm{ml}$ per minute less than in the vasodilated kidney despite the marked differences in sodium excretion.

These relationships between renal hemodynamics and sodium excretion during the major 
phases of the experiments are summarized in Figure 2.

Comparison of equipressor infusions of angiotensin and norepinephrine during unilateral renal vasodilatation. After collections during the stable phase of unilateral renal vasodilatation, an infusion of angiotensin ( $5 \mu \mathrm{g}$ per minute) or norepinephrine $(10 \mu \mathrm{g}$ per minute) was begun intrave- nously. After 20 to 30 minutes when blood pressure and urine flow were stable, collections for clearances were made, and the infusion of the pressor was discontinued. Another 15 to $30 \mathrm{~min}$ utes was allowed for the blood pressure to fall and the urine flow to decrease, and then the alternate pressor was infused intravenously. Usually the rate of infusion of the second pressor required 5 to

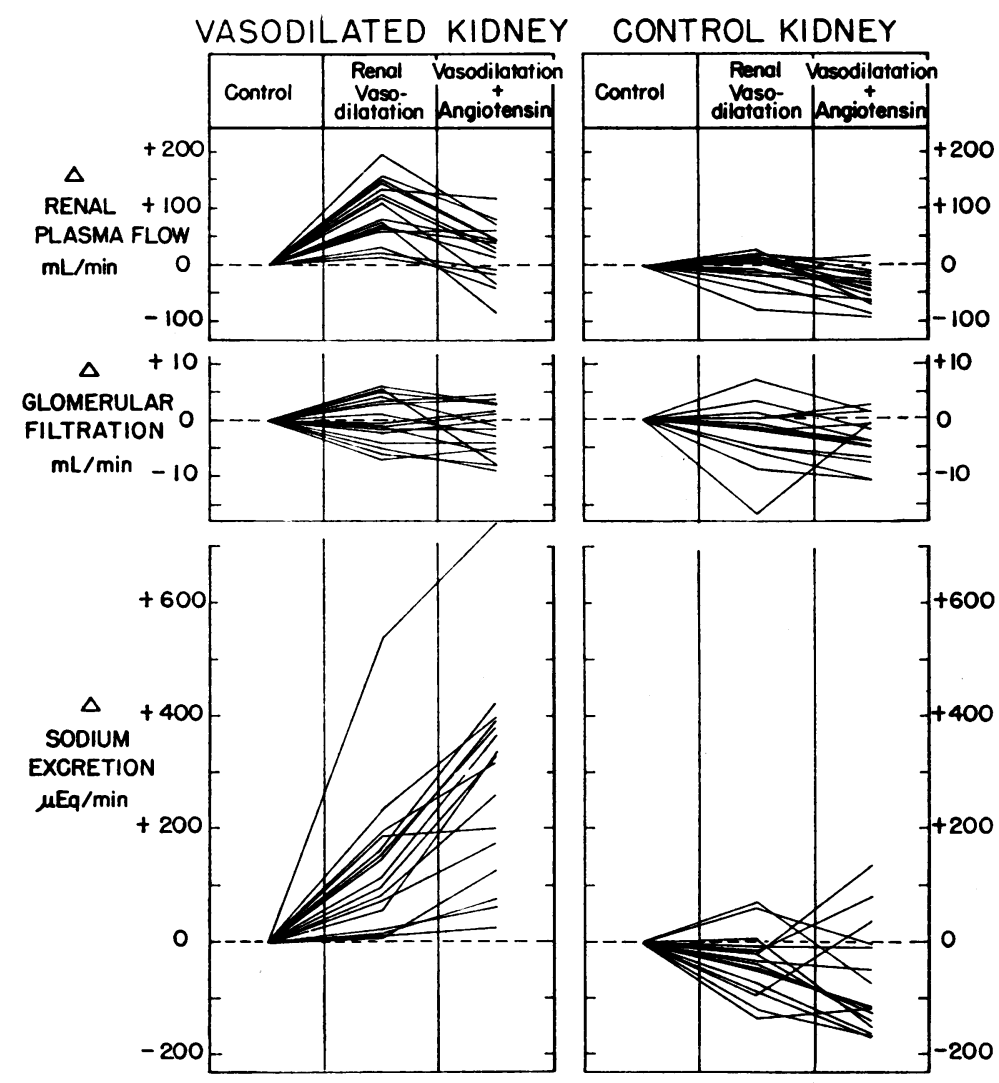

Fig. 2. EFFECTS OF INFUSION OF ANGIOTENSIN DURING UNILATERAL RENAL VASODILATATION ON RENAL HEMODYNAMICS AND SODIUM EXCRETION. The means of three or more uniform collections are represented in each column for each experiment (experiments 1 to 16). The clearance of PAH rather than true renal plasma flow is shown for control kidneys. During unilateral vasodilatation alone increased renal plasma flow was accompanied by increased sodium excretion and variable changes in glomerular filtration, whereas sodium excretion usually decreased in control kidneys with similar changes in glomerular filtration, but with unchanged or reduced plasma flow $\left(\mathrm{C}_{\mathbf{P A B}}\right)$. The superimposition of angiotensin uniformly resulted in a further increase in sodium excretion by vasodilated kidneys despite variable changes in glomerular filtration and a return toward control of renal plasma flow. During the infusion of angiotensin sodium excretion by control nonvasodilated kidneys exceeded control rates in only three experiments despite changes in glomerular filtration similar to those in vasodilated experimental kidneys. In any individual experiment plasma flow $\left(\mathrm{C}_{\mathrm{PAH}}\right)$ during the infusion of angiotensin was lower in the control kidney than in the experimental kidney. 
TABLE IV

Comparison of the effects of equipressor infusions of angiotensin and norepinephrine on renal hemodynamics and sodium excretion during unilateral renal vasodilatation

\begin{tabular}{|c|c|c|c|c|c|c|c|c|c|c|c|c|c|c|c|}
\hline \multirow[b]{2}{*}{ Experiment } & & \multicolumn{2}{|c|}{$\mathrm{V}$} & \multicolumn{2}{|c|}{ GFR } & \multicolumn{2}{|c|}{$\mathrm{CPAH}_{\mathrm{PaH}}$} & \multirow[b]{2}{*}{ EPAH } & \multirow[b]{2}{*}{ RPF } & \multirow[b]{2}{*}{ NCPF } & \multicolumn{2}{|c|}{$\mathrm{UNaV}_{\mathrm{Na}}$} & \multicolumn{2}{|c|}{$\frac{T_{\mathrm{Na}}}{\mathrm{F}_{\mathrm{Na}}} \times 100^{*}$} & \multirow{2}{*}{$\begin{array}{c}\text { Arterial } \\
\text { pressure }\end{array}$} \\
\hline & & $\mathbf{R}$ & L & $\mathbf{R}$ & L & $\mathbf{R}$ & $\mathrm{L}$ & & & & $\mathbf{R}$ & L & $\mathbf{R}$ & $\mathrm{L}$ & \\
\hline & & \multicolumn{2}{|c|}{$m l / \min$} & \multicolumn{2}{|c|}{$m l / m i n$} & \multicolumn{2}{|c|}{$m l / m i n$} & & min & $\begin{array}{l}\text { min } \\
\text { min }\end{array}$ & \multicolumn{2}{|c|}{$\mu E q / \min$} & \multicolumn{2}{|c|}{$\%$} & $m m \mathrm{Hg}$ \\
\hline \multirow[t]{5}{*}{$17 . \dagger$} & Control & 1.08 & & 38 & & 93 & & & & & 198 & 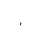 & 96.4 & & 126 \\
\hline & Acetylcholine & 2.00 & & 39 & & 114 & & & & & 295 & & 94.8 & & 116 \\
\hline & Angiotensin & 5.55 & & 43 & & 109 & & & & & 686 & & 89.1 & & 167 \\
\hline & Norepinephrine & 3.59 & & 39 & & 89 & & & & & 477 & & 91.8 & & 159 \\
\hline & Angiotensin & 3.94 & & 37 & & 84 & & & & & 515 & & 90.6 & & 145 \\
\hline \multirow[t]{5}{*}{$18 . \ddagger$} & Control & 0.26 & 0.22 & & & & & & & & 13 & 10 & & & 150 \\
\hline & Acetylcholine & 0.21 & 0.53 & 46 & 39 & 135 & 164 & 0.770 & 213 & 47 & 7 & 91 & 99.9 & 98.4 & 136 \\
\hline & Norepinephrine & 0.19 & 2.28 & 39 & 41 & 135 & 150 & 0.773 & 194 & 44 & 9 & 416 & 99.8 & 93.2 & 173 \\
\hline & Angiotensin & 0.33 & 3.84 & 36 & 38 & 78 & 126 & 0.750 & 168 & 42 & 38 & 507 & 99.3 & 91.0 & 173 \\
\hline & Norepinephrine & 0.17 & 1.84 & 44 & 37 & 98 & 111 & 0.732 & 152 & 41 & 5 & 311 & 99.9 & 94.3 & 169 \\
\hline \multirow[t]{5}{*}{19.7} & Control & 0.60 & 0.56 & & & & & & & & 130 & 126 & & & 139 \\
\hline & Acetylcholine & 0.47 & 2.55 & 32 & 38 & 99 & 198 & 0.655 & 302 & 104 & 76 & 288 & 98.3 & 94.9 & 129 \\
\hline & Angiotensin & 0.18 & 4.76 & 34 & 43 & 70 & 114 & 0.861 & 132 & 18 & 14 & 464 & 99.7 & 92.4 & 151 \\
\hline & Norepinephrine & 0.05 & 3.30 & 16 & 40 & 40 & 111 & 0.852 & 130 & 19 & 2 & 387 & 99.9 & 93.9 & 154 \\
\hline & Angiotensin & 0.10 & 4.01 & 37 & 37 & 80 & 102 & 0.827 & 123 & 21 & 2 & 347 & 99.9 & 93.6 & 147 \\
\hline \multirow[t]{5}{*}{20.} & Control & 1.38 & 1.83 & 35 & 32 & 97 & 90 & 0.904 & 100 & 10 & 261 & 315 & 94.8 & 93.0 & 140 \\
\hline & Acetylcholine & 0.30 & 3.99 & 32 & 36 & 81 & 131 & 0.762 & 172 & 41 & 53 & 539 & 98.9 & 89.5 & 116 \\
\hline & Norepinephrine & 0.14 & 5.35 & 32 & 35 & 71 & 105 & 0.836 & 126 & 21 & 10 & 693 & 99.8 & 86.1 & 167 \\
\hline & Angiotensin & 0.14 & 4.79 & 31 & 30 & 65 & 81 & 0.752 & 108 & 27 & 11 & 589 & 99.8 & 86.2 & 158 \\
\hline & Norepinephrine & 0.09 & 5.07 & 23 & 25 & 51 & 69 & 0.720 & 96 & 27 & 5 & 613 & 99.9 & 83.3 & 163 \\
\hline \multirow[t]{5}{*}{21.} & Control & 0.55 & 0.80 & 34 & 29 & 114 & 110 & 0.783 & 140 & 30 & 130 & 166 & 97.4 & 96.0 & 145 \\
\hline & Acetylcholine & 0.26 & 2.74 & 31 & 33 & 99 & 161 & 0.429 & 375 & 214 & 66 & 429 & 98.5 & 91.0 & 143 \\
\hline & Angiotensin & 0.05 & 5.72 & 5 & 34 & 12 & 124 & 0.516 & 240 & 116 & 13 & 785 & 98.2 & 84.5 & 195 \\
\hline & Norepinephrine & 0.02 & 4.50 & 5 & 35 & 13 & 105 & 0.655 & 160 & 55 & 2 & 620 & 99.7 & 88.1 & 187 \\
\hline & Angiotensin & 0.06 & 5.50 & 13 & 35 & 34 & 103 & 0.624 & 165 & 62 & 8 & 689 & 99.6 & 86.4 & 188 \\
\hline
\end{tabular}

* Additional abbreviation: $\left(\mathrm{T}_{\mathrm{Na}} / \mathrm{F}_{\mathrm{Na}}\right) \times \mathbf{1 0 0}=$ per cent of filtered sodium reabsorbed.

t Urine collected only from right kidney and no renal venous samples collected.

† Urine collected only from right kidney and no renal venous samples collected.

10 minutes of adjustment to achieve a blood pressure similar to that present during the initial infusion. After collections were made during infusion of the second pressor, the same sequence was followed to return to infusion of the first pressor agent. The infusion of acetylcholine ( $40 \mu \mathrm{g}$ per minute) was continued uninterrupted into the left renal artery. The results of these 5 studies are summarized in Table IV. Both angiotensin and norepinephrine decreased RPF below the levels present during vasodilatation alone, and both agents produced decreases in $\mathrm{C}_{\mathbf{P A B}}$ in the control kidney. However, during the infusion of the pressor agents $\mathrm{C}_{\mathrm{PAH}}$ was greater in the vasodilated kidney then in the control kidney. Norepinephrine resulted in increases in sodium excretion by the vasodilated kidneys and decreases in sodium excretion by control kidneys, responses qualitatively similar to those observed during the infusion of angiotensin. Also, the increased sodium excretion by the vasodilated kidneys during the infusion of norepinephrine was not necessarily associated with increased GFR (experiments 18 and 20, Table IV). However, in all but one study (experiment 20) the absolute rate of sodium excretion was greater, and the over-all fractional reabsorption of sodium was less during the infusion of angiotensin than during the infusion of norepinephrine. These small differences between the effects of angiotensin and norepinephrine on sodium excretion and reabsorption did not relate to differences in GFR. Thus, the infusion of equipressor amounts of angiotensin or norepinephrine resulted in qualitatively similar changes in hemodynamics and sodium excretion in the vasodilated kidneys.

\section{Discussion}

The present results agree with previous studies indicating that renal vasodilatation per se may increase sodium excretion and decrease the net tubular reabsorption of sodium $(8,14)$. In our study unilaterally increased renal plasma flow re- 
sulting from three different vasodilators was accompanied by decreased tubular reabsorption of sodium. These observations strengthen the concept that it is the vasodilatation which results in diminished reabsorption of sodium and not some more direct effect of the infused agent on tubular transport (14). We have suggested previously that increased renal medullary blood flow may diminish the absolute reabsorption of sodium by the ascending limb of Henle's loop (4, 5), and Leyssac has suggested that angiotensin may diminish proximal tubular reabsorption of sodium (15). Although the effects have not been entirely predictable, angiotensin does produce natriuresis under some conditions (16-19). If diminished renal blood flow increased sodium reabsorption in Henle's loop or more distal portions of the nephron, then the vasoconstrictor effects of angiotensin could mask the effects that the agent could have to diminish proximal reabsorption by enhancing sodium reabsorption at a more distal site, and perhaps also by reducing GFR and the filtered load of sodium. If so, then induced renal vasodilatation could minimize the vascular effects of angiotensin and permit the agent to produce natriuresis as the result of diminished proximal reabsorption of sodium. To a large extent the present results are consistent with this view. In the presence of renal vasodilatation the infusion of angiotensin invariably was associated with natriuresis that in some cases was comparable to that associated with saline loading $(2,5)$.

This angiotensin-induced natriuresis was accompanied by a reduction in RPF and in most cases by a reduction in GFR. In nonvasodilated control kidneys the infusion of angiotensin usually produced decreased sodium excretion in the presence of lower plasma flows (as judged by the clearance of $\mathrm{PAH}$ ) than were present simultaneously in the natriuretic vasodilated kidneys. It did not appear likely that vasodilatation permitted the natriuresis during the systemic infusion of angiotensin simply by maintaining a higher GFR and filtered load of sodium, since in 10 experiments GFR in control kidneys undergoing sodium retention was similar to or greater than GFR in the vasodilated natriuretic kidneys. Therefore, it appears that the maintenance of some critical level of blood flow was necessary to demonstrate the natriuretic effect of angiotensin. Even though the clearance of $\mathrm{PAH}$ during the infusion of angiotensin was greater in vasodilated than in control kidneys, this measurement, as well as total renal plasma flow and noncortical plasma flow, was reduced below the levels present during vasodilatation alone. Therefore, the additional natriuretic effect of angiotensin cannot be attributed to a further increase in any of these hemodynamic measurements. These observations make it unlikely that increased renal blood per se decreases the reabsorption of sodium as suggested previously (5, 14).

The present studies do not demonstrate that angiotensin exerts a direct effect to decrease the tubular reabsorption of sodium, and the results are more consistent with the view that it is the pressor effect of angiotensin that diminishes sodium reabsorption. In support of this conclusion are the present observations that angiotensin resulted in natriuresis only when given in pressor amounts, and that both angiotensin and norepinephrine produced qualitatively and quantitatively similar changes in renal hemodynamics and sodium excretion when given in equipressor amounts. However, since each of these pressor agents produced natriuresis only in the presence of induced renal vasodilatation, it is apparent that some critical level of renal blood flow or renal vascular resistance is necessary for the effect of increased arterial pressure to decrease the reabsorption of sodium. Since the natriuretic effect of the pressors was not associated with a further increase in hemodynamics in the vasodilated kidney, the natriuresis appears to be the result of the increased perfusion pressure per se. There is other evidence that increased renal perfusion pressure may increase sodium excretion (20-24), and that this effect of pressure is mediated through intrarenal mechanisms $(20,22)$. The present studies extend such observations and demonstrate that the natriuretic effect of increased arterial pressure is dependent upon prevention of the intense renal vasoconstriction usually associated with the infusion of angiotensin or norepinephrine, since vasoconstriction was minimized in the vasodilated kidneys.

The mechanism whereby increased renal perfusion pressure could decrease sodium reabsorption is unknown. The dependence of this effect of perfusion pressure on induced renal vasodilatation suggests that transmission of the increased perfu- 
sion pressure to some sensitive portion of the renal vasculature may be responsible for this natriuretic effect. There is some evidence that proximal tubular reabsorption may relate in some direct manner to tubular distension (25). If so, then constriction of the lumen of the proximal tubule should decrease the reabsorption of sodium and water at that site. If the increased arterial pressure produced in our studies were transmitted to some extent to the postglomerular capillary, then capillary perfusion pressure would be increased, and as a result the cortical interstitial volume should increase. Such an increased interstitial volume could result in some degree of collapse of the tubule, especially when the flow into the tubule as judged by GFR was unchanged or decreased. The effect of vasodilatation alone to decrease sodium reabsorption could be explained by the same mechanism, since a reduction of precapillary resistance would allow a more complete transmission of the existing perfusion pressure to the capillary circulation. Confirmation or rejection of such a mechanism to account for these hemodynamic effects on sodium reabsorption will be dependent upon direct measurements of changes in interstitial volume, tubular distension, and reabsorption in response to hemodynamic changes such as those produced in the present studies.

It does not appear likely that the natriuresis observed in the present studies was due to some direct synergistic effects of the agents on tubular transport, since similar results were observed with combinations of angiotensin or norepinephrine and acetylcholine, bradykinin, or kallidin. A1though the natriuretic effect of angiotensin quantitatively was slightly greater than that observed during equipressor infusions of norepinephrine, the effects of the two agents were qualitatively the same. Therefore, even though angiotensin may have a direct effect to decrease the tubular reabsorption of sodium, the present study does not permit such a conclusion. Laragh and his associates found striking differences in the natriuretic effects of angiotensin and norepinephrine in patients with cirrhosis who exhibited natriuretic responses to infusions of angiotensin (18), in contrast to the similar effects of the two agents observed in the present study. However, it is possible that subtle differences in the renal vasoconstriction produced by the agents could account for the different responses in the patients studied by these latter authors (18), and in the present study such a possible difference in the renal vascular effects of the two agents was minimized by the induced renal vasodilatation.

\section{Summary}

The combined effects of unilateral renal vasodilatation and angiotensin infusion on renal hemodynamics and sodium excretion and reabsorption were studied in anesthetized hydropenic dogs. Unilateral renal vasodilatation alone with either acetylcholine, bradykinin, or kallidin resulted in an ipsilateral increase in renal plasma flow and an ipsilateral decrease in net tubular reabsorption of sodium. The infusion of angiotensin or norepinephrine in the presence of unilateral renal vasodilatation resulted in a sustained marked increase in sodium excretion and decreased sodium reabsorption by the vasodilated kidney. These changes occurred in association with decreases in glomerular filtration rate, clearance of $p$-aminohippurate, renal plasma flow, and "noncortical" plasma flow. Sodium excretion usually decreased in control nonvasodilated kidneys during the infusion of angiotensin or norepinephrine, although glomerular filtration rate was often similar in the two kidneys. The clearance of $p$-aminohippurate, however, was always distinctly lower in the control nonvasodilated kidney.

These results are consistent with the view that the proper combination of two physiologically important variables, arterial pressure and renal vascular resistance, can effect large changes in the tubular reabsorption of sodium, probably through intrarenal mechanisms. We suggest, therefore, that changes in these two variables may be of major importance in the regulation of sodium excretion.

\section{Acknowledgments}

The authors are indebted to Susan Howard and Barbel Juergens for their assistance with these studies.

\section{References}

1. De Wardner, H. E., I. H. Mills, W. F. Clapham, and C. J. Hayter. Studies on the efferent mechanism of the sodium diuresis which follows the administration of intravenous saline in the dog. Clin. Sci. 1961, 21, 249. 
2. Levinsky, N. G., and R. C. Lalone. The mechanism of sodium diuresis after saline infusion in the dog. J. clin. Invest. 1963, 42, 1261.

3. Rector, F. C., Jr., G. Van Giesen, F. Kiil, and D. W. Seldin. Influence of expansion of extracellular volume on tubular reabsorption of sodium independent of changes in glomerular filtration rate and aldosterone activity. J. clin. Invest. 1964, 43, 341.

4. Earley, L. E., and R. M. Friedler. Observations on the mechanism of decreased tubular reabsorption of sodium and water during saline loading. J. clin. Invest. 1964, 43, 1928.

5. Earley, L. E., and R. M. Friedler. Changes in renal blood flow and possibly the intrarenal distribution of blood during the natriuresis accompanying saline loading in the dog. J. clin. Invest. 1965, 44, 929.

6. Dirks, J. H., W. J. Cirksena, and R. W. Berliner. The effect of saline infusion on sodium reabsorption by the proximal tubule of the dog. J. clin. Invest. 1965, 44, 1160.

7. Vander, A. J. Effects of acetylcholine, atrophine, and physostigmine on renal function in the dog. Amer. J. Physiol. 1964, 206, 492.

8. Pinter, G. G., C. C. C. O'Morchoe, and R. S. Sikand. Effect of acetylcholine on urinary electrolyte excretion. Amer. J. Physiol. 1964, 207, 979.

9. Williams, R. L., J. E. Pearson, Jr., and M. K. Carter. The saluretic effects of arecoline hydrochloride infused into the left renal artery of dogs. J. Pharmacol. exp. Ther. 1965, 147, 32.

10. McDonald, R. H., Jr., L. I. Goldberg, J. L. McNay, and E. P. Tuttle, Jr. Effect of dopamine in man: augmentation of sodium excretion, glomerular filtration rate, and renal plasma flow. J. clin. Invest. 1964, 43, 1116.

11. Gombos, E. A., and T. H. Lee. Renal functional response to pyrogen induced renal hyperemia (abstract). Clin. Res. 1965, 13, 306.

12. Webster, M. E., and J. P. Gilmore. Influence of kallidin-10 on renal function. Amer. J. Physiol. 1964, 206, 714.

13. Meyer, M. B., and L. I. Goldberg. Natriuretic effect of papaverine. Fed. Proc. 1965, 24, 258.

14. Earley, L. E., and R. M. Friedler. Studies on the mechanism of natriuresis accompanying increased renal blood flow and its role in the renal response to extracellular volume expansion. J. clin. Invest. 1965, 44, 1857.

15. Leyssac, P. P. The effect of partial clamping of the renal artery on pressures in the proximal and distal tubules and peritubular capillaries of the rat kidney. Acta physiol. scand. 1964, 62, 449.

16. Hughes-Jones, N. C., G. W. Pickering, P. H. Sanderson, H. Scarborough, and J. Vandenbroucke. The nature of the action of renin and hypertension on renal function in the rabbit. J. Physiol. (Lond.) 1949, 109, 288.

17. Corcoran, A. C., and F. Del Greco. Mechanisms of renin diuresis in dogs. Fed. Proc. 1955, 14, 31.

18. Laragh, J. H., P. J. Cannon, C. J. Bentzel, A. M. Sicinski, and J. I. Meltzer. Angiotensin II, norepinephrine, and renal transport of electrolytes and water in normal man and in cirrhosis with ascites. J. clin. Invest. 1963, 42, 1179.

19. Healy, J. K., C. Barcena, J. M. B. O'Connell, and G. E. Schreiner. Renal and pressor action of angiotensin in the normal dog. Amer. J. Physiol. 1965, 208, 1093.

20. Selkurt, E. E. Effect of pulse pressure and mean arterial pressure modification on renal hemodynamics and electrolyte and water excretion. Circulation 1951, 4, 541 .

21. Tobian, L., K. Coffee, D. Ferreira, and J. Meuli. The effect of renal perfusion pressure on the net transport of sodium out of distal tubular urine as studied with the stop-flow technique. J. clin. Invest. 1964, 43, 118.

22. Selkurt, E. E., I. Womack, and W. N. Dailey. Mechanisms of natriuresis and diuresis during elevated renal arterial pressure. Amer. J. Physiol. 1965, 209, 95.

23. McDonald, S. J., and H. E. de Wardener. The relationship between the renal arterial perfusion pressure and the increase in sodium excretion which occurs during an infusion of saline. Nephron $1965,2,1$.

24. Handley, C. A., and J. H. Moyer. Unilateral renal adrenergic blockade and the renal response to vasopressor agents and to hemorrhage. J. Pharmacol. exp. Ther. 1954, 112, 1.

25. Brunner, F. P., F. C. Rector, Jr., and D. W. Seldin. Regulation of proximal tubular fluid reabsorption as studied by stopped flow microperfusion in the rat kidney (abstract). J. clin. Invest. 1965, 44, 1031. 